\title{
Necrobiosis Lipoidica in the Absence of Diabetes Mellitus: A Case Report and an Analysis of 116 Japanese Cases
}

\author{
Ayumi Korekawaka, Koji Nakajima, Hajime Nakano, Daisuke Sawamura* \\ Department of Dermatology, Hirosaki University Graduate School of Medicine, Hirosaki, Japan \\ Email: ${ }^{*}$ m981027@cc.hirosaki-u.ac.jp
}

Received 23 October 2014; revised 22 November 2014; accepted 3 December 2014

Copyright (C 2014 by authors and Scientific Research Publishing Inc.

This work is licensed under the Creative Commons Attribution International License (CC BY). http://creativecommons.org/licenses/by/4.0/

\section{c) (i) Open Access}

\section{Abstract}

A 60-year-old Japanese woman was referred to our hospital for yellow-brown plaques accompanied by ulceration on her left lower leg. Her medical history included neither diabetes mellitus nor minor trauma. A histopathological examination of the plaques showed necrobiotic changes within the dermal collagen surrounded by granulomas that comprised lymphocytes, histiocytes, and giant cells. The lower dermis revealed fibrotic changes that extended into the subcutaneous tissue. The patient's blood glucose and glycated hemoglobin levels were within the normal ranges. We considered a diagnosis of necrobiosis lipoidica (NL) in the absence of diabetes mellitus. We reviewed 116 cases of NL that were reported in the Japanese medical literature between 1986 and 2014 and found that NL onset was most common in individuals of both sexes $\geq 60$ years of age. Previous reports that reviewed NL cases in the Japanese medical literature that were published during the1900s indicated that NL occurs in people $\geq 40$ years of age. We suggest that the aging population and increasingly longer life spans have increased the average age of NL onset in Japan. With regard to treatments, there were no effective treatments, but skin grafts were curative. NL treatment is very difficult, especially when ulcers are present; hence, we suggest that further research is needed to determine effective $\mathrm{NL}$ treatments.

\section{Keywords}

Peripheral Circulatory Disturbance, Ulceration, Trauma, Lower Leg

\section{Introduction}

Necrobiosis lipoidica (NL) is a rare and benign granulomatous disease that is associated with collagen degeneration and typically affects the lower legs of women. It is characterized by well-defined ulcerated plaques with

\footnotetext{
"Corresponding author.
}

How to cite this paper: Korekawaka, A., Nakajima, K., Nakano, H. and Sawamura, D. (2014) Necrobiosis Lipoidica in the Absence of Diabetes Mellitus: A Case Report and an Analysis of 116 Japanese Cases. Case Reports in Clinical Medicine, 3, 639-643. http://dx.doi.org/10.4236/crcm.2014.312136 
indurate borders and atrophic centers that often impair patient quality of life when form ulcerations in skin lesions, especially in lower legs.

NL is associated with diabetes mellitus in $80 \%-90 \%$ of cases. Although its pathogenesis has been discussed in the context of diabetes mellitus, its co-occurrence with peripheral circulatory disturbances and autoimmune disorders has yet to be established. There are no clear specific treatments for NL. Here we describe the case of a Japanese woman who was diagnosed with NL in the absence of diabetes mellitus and report on an analysis of 116 Japanese NL cases.

\section{Case Report}

A 60-year-old Japanese woman was referred to our hospital in June 2014 with a 2-year history of yellow-brown plaques on her lower left leg. The plaques had gradually worsened over time. The lesions were irregularly shaped, well-circumscribed, atrophic yellow-brown plaques, and the largest was accompanied by a small ulcer (Figure 1(a), Figure 1(b)). There was no leg edema, associated pain, or itching as well as no varices. Her medical history did not include diabetes mellitus, metabolic disorders, or minor trauma. She had stitched clothing for many years and stood for long periods of time as she worked. The patient's lesions were clinically diagnosed as $\mathrm{NL}$, and we performed a skin biopsy.

A histopathological examination showed necrobiotic changes within the dermal collagen that were surrounded by granulomas that comprised lymphocytes, histiocytes, and giant cells (Figures 1(c)-(e)). The lower dermis revealed fibrotic changes that extended into the subcutaneous tissue. The blood vessels in that region did not show any particularly abnormal changes. The epidermis was mildly atrophic. Laboratory test results, including blood glucose and glycated hemoglobin levels, were within the normal ranges. A 75-goral glucose tolerance test produced normal results.

We treated the patient with topical corticosteroids but saw no noticeable improvement. Given the diagnosis of NL in the absence of diabetes mellitus, we administered topical therapy that comprised alprostadil alfadex ointment $(0.003 \%)$. By 2 months after the treatment initiation, the lesions had decreased in size.

\section{Discussion}

NL is an idiopathic chronic granulomatous inflammatory disorder characterized by collagen degeneration, granuloma formation, fat deposition, and thickening of the blood vessel walls. NL is often associated with diabetes mellitus, thyroid dysfunction, sarcoidosis, rheumatoid arthritis, inflammatory bowel disease, and peripheral circulatory disturbances, and most cases of NL are idiopathic [1]. The most commonly affected regions are the pretibial areas.

We reviewed 116 NL cases that were reported in the Japanese medical literature between 1986 and 2014 including the present case. Thirteen menaged 21 - 75 years and 103 women aged 31 - 86 years were evaluated with regard to their epidemiological data, the presence of ulcers, lesion, laboratory test results, treatment provided, and treatmenteffects. NL was considerably more frequent in women (89\%) (Figure 2(a)). NL onset was most common when people of both sexes were aged $\geq 60$ years, and the average age of NL onset was 55.5 years in women and 56.4 years in men (Figure 2(b), Figure 2(c)). Reports from countries other than Japan indicated that NL occurs during the third or fourth decades of life in both sexes [2]-[4] Previous reports that reviewed NL cases in the Japanese medical literature published during the 1900s indicated that the average age range at NL onset was the 40s in both sexes [5]. However, reports that reviewed NL cases in the Japanese medical literature published during the 2000s indicated that the average age at NL onset was $\geq 50$ years in both sexes [6] [7]. We suggest that the aging population and extended lifes pans have increased the average age of NL onset in Japan.

The incidence of diabetes mellitus among people with NL is reportedly $77 \%$ for men and $30 \%$ for women. In $48 \%$ of men, NL lesions were found in areas other than the pretibial regions, including the forearms, chest, abdomen, thighs, fingers, scrotum, and penis. In contrast, only 8\% of women had lesions in atypical locations, including the face, back, groin, abdomen, and chest (Figure 2(d)). We found that the presence of diabetes mellitus with NL and atypical lesion locations occurred predominantly in men.

Of the patients whose cases were reviewed, ulceration of the NL lesions occurred in $14 \%$ and trauma preceded NL in $23 \%$ of men and in $19 \%$ of women. Although $9.4 \%$ of all of cases reviewed had neither metabolic disorders nor trauma, they did have histories that were indicative of circulatory disturbances, which included 

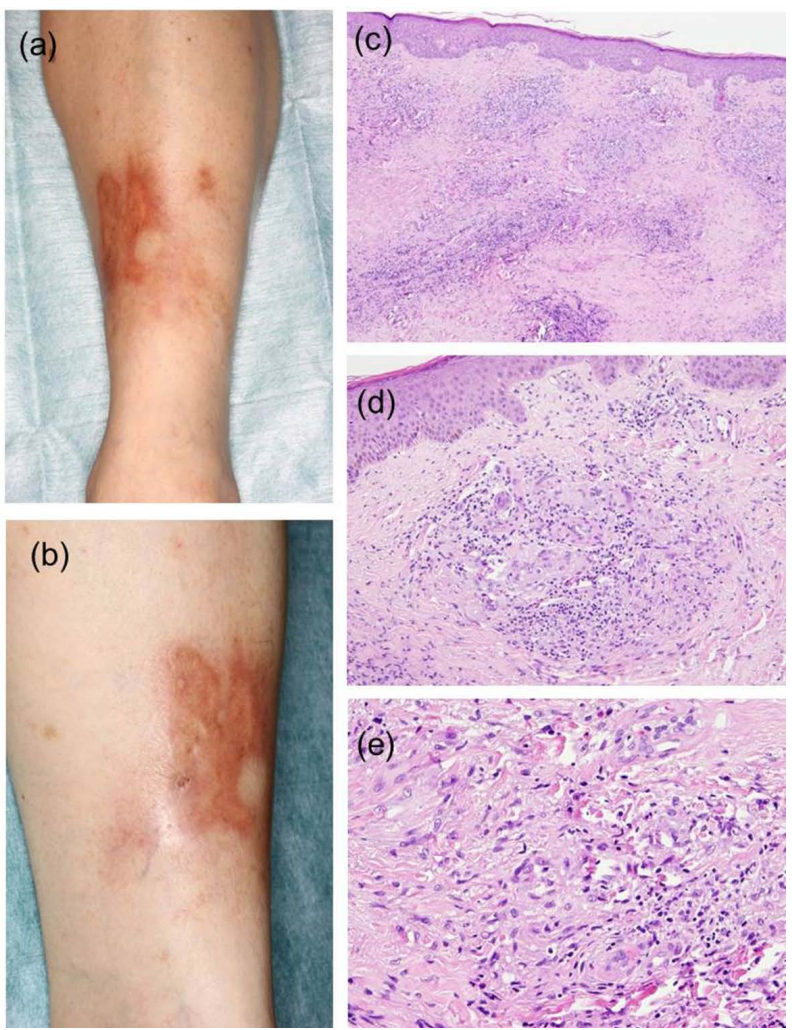

Figure 1. Clinical manifestations and histopathological findings. (a) (b) Irregularly shaped, well-circumscribed, atrophic yellow-brown necrobiosis lipoidica plaques, one of which is accompanied by a small ulcer on the patient's lower left leg; (c)-(e) Necrobiotic changes within the dermal collagen that are surrounded by granulomasthatcomprise lymphocytes, histiocytes, and giant cells. Fibrotic changes that are apparent in the lower dermis extend into the subcutaneous tissue (hematoxylin and eosin, Figure 1(c) 40×, Figure 1(b) 100×, and Figure 1(e) 400×).

(a) NL 116cases

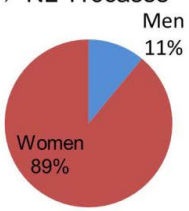

(b) Women 103cases

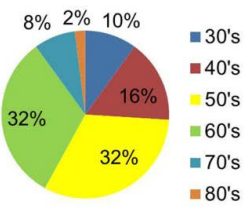

(c) Men 13cases

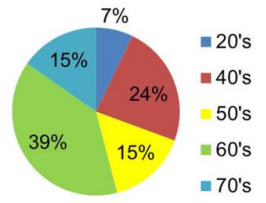

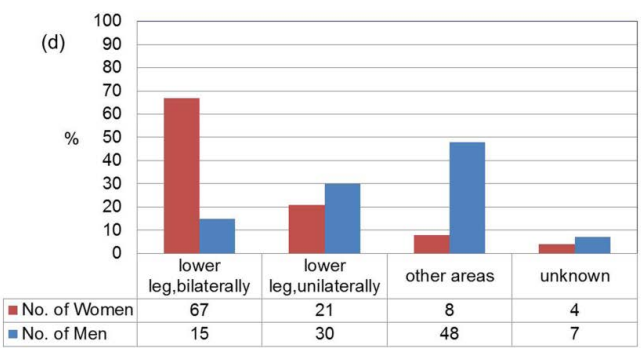

Figure 2. (a)-(c) Epidemiological data and lesion locations. Necrobiosis lipoidica (NL) is considerably more frequent in women and the onset is most common when people of both sexes are $\geq 60$ yearsof age; (d) NL lesions are found in areas other than the pretibial regions, including the forearms, chest, abdomen, thighs, fingers, scrotum, and penis in $48 \%$ of men.

standing for long periods of time while working, lymph edema of the affected parts, postoperative effects, and varices. Although there was no history of metabolic disorders, minor trauma, edema, or varices and there were no histopathological findings associated with the blood vessels in our case, the patient had worked for many years stitching clothing and had stood for long periods of time while she worked. We propose that her work had 
induced peripheral circulatory disturbances that triggered collagen degeneration.

Topical corticosteroids, the mainstay of NL treatment, were used in 25 cases. Aspirin (900 - $1000 \mathrm{mg} / \mathrm{day})$ and dipyridamole (150 - $225 \mathrm{mg} /$ day) given in combination, oral corticosteroids (20 - 30 mg/day), fludroxycortide tape, and herbal preparations including modified Merry Life Powder, which comprised a rhubarb and moutan bark decoction, were effective, and operations comprising excisions or skin grafts were curative (Table 1). Many cases were given several different treatment types. Topical tacrolimus was used to treat three patients with

Table 1. Treatment options for necrobiosis lipoidica and treatment outcomes.

\begin{tabular}{|c|c|c|}
\hline Treatment & No. of cases & No. of effective cases \\
\hline \multicolumn{3}{|l|}{ No. of methods: one } \\
\hline Topical corticosteroids & 25 & 11 \\
\hline Fludroxycortide tape $\left(4 \mu \mathrm{g} / \mathrm{cm}^{2}\right)$ & 3 & 2 \\
\hline Moisturizer & 2 & 0 \\
\hline Anti-ulcer agents & 3 & 3 \\
\hline Tacrolimus & 2 & 1 \\
\hline Oral corticosteroids (20 - 30 mg/day) & 7 & 6 \\
\hline Tranilast & 2 & 1 \\
\hline Tocopherol nicotinate & 3 & 2 \\
\hline Aspirin & 4 & 2 \\
\hline Herbal preparations & 2 & 2 \\
\hline Ethyl icosapentate & 1 & 1 \\
\hline Local injection corticosteroids & 3 & 1 \\
\hline Others compression therapy & 1 & 1 \\
\hline PDT (photodynamic therapy) & 1 & 1 \\
\hline PUVA (psoralen plus ultraviolet) & 2 & 1 \\
\hline operation (excision or skin graft) & 5 & 5 \\
\hline \multicolumn{3}{|l|}{ No. of methods: two } \\
\hline Topical only corticosteroids plus moisturizer & 4 & 2 \\
\hline Corticosteroids plus anti-ulcer agents & 2 & 1 \\
\hline Tacrolimus plus corticosteroids & 1 & 0 \\
\hline Oral plus topical tranilast (oral) plus corticosteroids(topical) & 1 & 1 \\
\hline Aspirin (oral) plus corticosteroids(topical) & 1 & 0 \\
\hline Oral only tocopherol nicotinate plus aspirin & 1 & 1 \\
\hline Aspirin (900 - 1000 mg/day) and dipyridamole (150 - 225 mg/day) & 5 & 5 \\
\hline Others losing weight plus topical corticosteroids & 1 & 0 \\
\hline Losing weight plus maintaining adequate glucose control & 2 & 1 \\
\hline Compression therapy plus topical corticosteroids & 1 & 0 \\
\hline PUVA plus compression therapy & 1 & 0 \\
\hline PUVA plus topical corticosteroids & 1 & 1 \\
\hline Near-infrared light treatment plus topical $0.003 \%$ alprostadil alfadex ointment & 1 & 1 \\
\hline \multicolumn{3}{|l|}{ No. of methods: three } \\
\hline Compression therapy plus topical corticosteroids plus sarpogrelate hydrochloride & 1 & 1 \\
\hline Oral tranilast plus topical corticosteroids plus compression therapy & 1 & 1 \\
\hline PUVA plus compression therapy plus corticosteroid local injection & 1 & 1 \\
\hline $\begin{array}{l}\text { Oral corticosteroids (30 mg/day) plus operation (excision or skin graft) } \\
\text { plus corticosteroidlocal injection }\end{array}$ & 1 & 1 \\
\hline \multicolumn{3}{|l|}{ No. of methods:more than three } \\
\hline Oral clarithromycin plus oral tranilast plus topical corticosteroids & 1 & \\
\hline plus topical anti-ulcer agents plus topical $0.003 \%$ alprostadil alfadex ointment & & 1 \\
\hline Methods: unknown & 23 & \\
\hline
\end{tabular}


NL, but no notable improvements were observed. While operative procedures seem to heal NL completely, there is a risk of relapse because of vascular damage and koebnerization; hence, we should be careful when making treatment decisions.

\section{Conclusion}

Treating NL is very difficult, especially cases of ulcerated NL, and squamous cell carcinomais often associated with ulcerated NL [8]. We suggest the need for further research to determine effective treatments for NL.

\section{Conflict of Interest Statement}

The authors declare no conflicts of interest.

\section{References}

[1] Chung, C.G., Rosengrant, A., Helm, K.F. and Shupp, D.L. (2014) Necrobiosis Lipoidica Occurring in a Patient with Rheumatoid Arthritis on Concurrent Tumor Necrosis Factor- $\alpha$ Inhibitor Therapy. International Journal of Dermatology. http://dx.doi.org/10.1111/ijd.12309

[2] Reid, S.D., Ladizinski, B., Lee, K., Baibergenova, A. and Alavi, A. (2013) Update on Necrobiosis Lipoidica: A Review of Etiology, Diagnosis, and Treatment Options. Journal of the American Academy of Dermatology, 69, 783-791. http://dx.doi.org/10.1016/j.jaad.2013.05.034

[3] Erfurt-Berge, C., Seitz, A.T., Rehse, C., Wollina, U., Schwede, K. and Renner, R. (2012) Update on Clinical and Laboratory Features in Necrobiosis Lipoidica: A Retrospective Multicentre Study of 52 Patients. European Journal of Dermatology, 22, 770-775.

[4] Pătraşcu, V., Giurcă, C., Ciurea, R.N., Georgescu, C.C. and Ciurea, M.E. (2014) Ulcerated Necrobiosis Lipoidica to a Teenager with Diabetes Mellitus and Obesity. Romanian Journal of Morphology and Embryology, 55, 171-176.

[5] Masatoshi, A., Kazunori, O., Osamu, I., Yoshiki, M., Toshiya, I. and Kyohei, S. (1999) Twocases of Necrobiosis Lipoidica-Its Relationships with Diabetes Mellitus and Preceding Trauma in the Japanese Patients. Rinsho Derma (Tokyo), 53, 529-532.

[6] Mariko, Y., Yasuhiko, M., Takekuni, N., Shinichiro, Y., Takashi, H. and Kenichiro, I. (2006) A Case of Necrobiosis Lipoidica without Diabetes Mellitus. Rinsho Derma (Tokyo), 60, 1020-1022.

[7] Misaki, O., Yoshihiro, S., Yuichi, T. and Seiichi, I. (2011) A Case of Necrobiosis Lipoidica Associated with Venous Insufficiency of Both Legs. Rinsho Derma (Tokyo), 65, 497-500.

[8] Uva, L., Freitas, J., Soares de Almeida, L., Vasques, H., Moura, C. and Miguel, D. (2013) Squamous Cell Carcinoma Arising in Ulcerated Necrobiosis Lipoidica Diabeticorum. International Wound Journal. http://dx.doi.org/10.1111/iwj.12206 
Scientific Research Publishing (SCIRP) is one of the largest Open Access journal publishers. It is currently publishing more than 200 open access, online, peer-reviewed journals covering a wide range of academic disciplines. SCIRP serves the worldwide academic communities and contributes to the progress and application of science with its publication.

Other selected journals from SCIRP are listed as below. Submit your manuscript to us via either submit@scirp.org or Online Submission Portal.
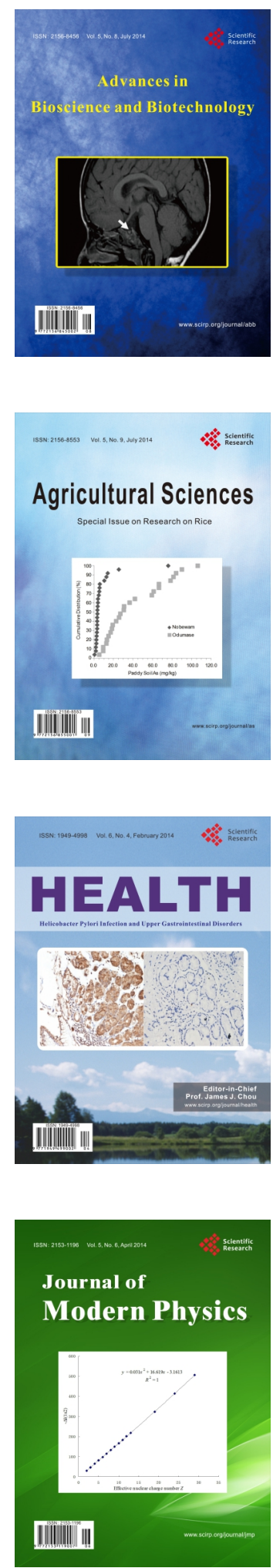
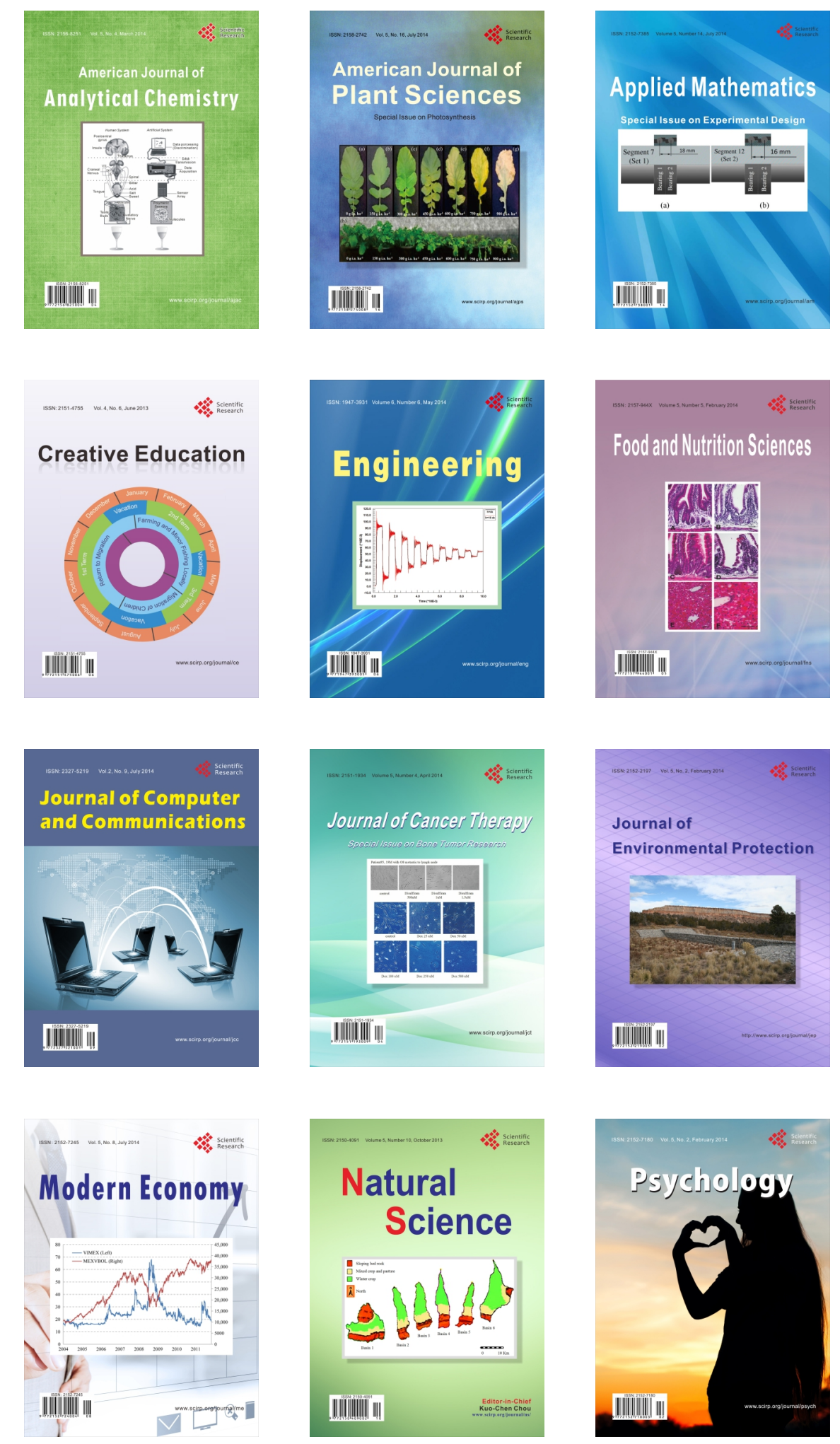